\title{
Table of national acts, EC directives, regulations and notices
}

African Growth Opportunities Act 2000

245

Brussels Regulation (Council Regulation 44/2001)

138

Commission Communication on VoIP OJ C369, 22.12.2000 59

Commission Notice 2004/C 101/02 (April 2004) 209

Commission Regulation (EC) No. 802/2004, April 2004

Commission Regulation 772/2004 (April 2004) 209

Council Directive 89/552/EEC (as amended by Council Directive 97/36/EC)

$120,126,128,151,154$

Directive (as amended) Directive 77/388/EEC

$121,127,134$

Directive 87/54/EEC

218

Directive 89/552/EEC (as amended)

154

Directive 90/388/EEC

Directive $91 / 250$

207

Directive 92/44 (annulled)

Directive 97/13 (annulled)

92

Directive 97/33 (annulled)

91,92

Directive 97/36/EC 120,154

Directive 98/10 (annulled)

92

Directive 98/34/EC

Directive 98/48/EC

Directive 2000/31/EC

127,153

Directive 2002/19/EC

$55,89,107,227$

Directive 2002/20/EC

$89,90,114$

Directive 2002/21/EC

Directive 2002/22/EC

Directive 2002/38/EC

74, 89, 91, 104, 110, 114, 217, 227, 228

Directive 2002/58/EC

$127,134,153$

Directive 2002/77/EC

EC Merger Regulation (EC) No. 139/2004

European Copyright Directive 2001/29/EC

European Council Decision 94/828/EC

Singapore Copyright (Amendment) Bill 2004

Technology Transfer Block Regulation EC 772/2004 
US Clayton Act

88, 108, 209

US Digital Millennium Copyright Act (DMCA) 1998

$207,241,243$

US Sherman Act

$88,108,209$

US Telecommunications Act 1996

$26,38,59,81,91,97-8,180$

US Trade Act 1974

240

US Trade Act 2002

240-43, 250, 272, 296, 329

US Uruguay Round Agreements Act (19 USC 3511(d)(15))

240 